\title{
Comparative Analysis of Online Shopping Behavior of Thai and Chinese Consumers
}

\author{
Krit Khwanngern $^{1}$, Varin Chouvatut ${ }^{2}$ and Weerakorn Ongsakul ${ }^{3}$ \\ ${ }^{1,2,3}$ Faculty of Information and Communication Technology, Mahidol University, \\ Nakhon Pathom, Thailand \\ ${ }^{1}$ khwanngern.krit@mahidol.ac.th
}

\begin{abstract}
In recent years, e-commerce has grown rapidly, and Thailand's e-commerce growth rate in Southeast Asia has also ranked first. Large and small businesses have increased their online sales business. Although the development speed of the traditional import and export economy has slowed down, e-commerce has increased strongly. E-commerce has the characteristics of shortening transaction links and reducing costs, enabling producers to directly face end consumers and reducing commodity prices. Thailand currently does not have an online shopping platform with domestic capital. They are all platforms with foreign capital, such as Shopee, Lazada, and Alibaba. Secondly, Thais can also purchase domestic products through Facebook and Instagram, similar to Chinese micro-businesses. Due to the different consumption habits of consumers in the two countries, the acceptance of online shopping is also different. To understand the online shopping behaviors of consumers in the two countries, this paper analyzes the online shopping behaviors of Thai and Chinese consumers through questionnaires and puts forward corresponding opinions to promote the development of ecommerce in Thailand. Furthermore, based on the survey and comparison, it analyzes the future development opportunities of Thailand's e-commerce and promotes the further improvement of Thailand's e-commerce business.
\end{abstract}

Keywords: E-commerce, Online shopping platform, Online buying behavior, Development opportunities

\section{Introduction}

With the continuous development of economic globalization, the achievements of information technology have begun to be used in economic and trade exchanges. As an active participant in economic globalization, Thailand's development in the trade field has made great changes. E-commerce has continued to become an important form of cross-border trade exchanges, and it has received increasing attention. In the traditional trade sales model, most trade behaviors occur when the importer enters the target importing country to complete the import of the goods, and then realizes the transfer of the goods from the exporting country to the importing country, and then realizes the domestic market distribution behavior. But now the application of Internet technology has led to the rise of e-commerce, and with the popularity of online shopping, the traditional trade transaction model is undergoing profound changes. The academic circles have paid more and more attention to this issue. For a long time, Thailand has pursued the development strategy of "economic diplomacy" [1]. While developing its

Article history:

Received (July 1, 2020), Review Result (August 5, 2020), Accepted (September 9, 2020) 
economy, it has carried out economic exchanges and cooperation with China in different aspects. China-Thailand economic and trade relations have been continuously improved, and economic exchanges have become more in-depth. As a result, the level of economy and trade has been continuously improved. Since the establishment of formal diplomatic relations between China and Thailand in 1975, the overall trade between the two countries has continued. The development of economic globalization has promoted the gradual transformation of international e-commerce to cross-border e-commerce. At present, Thailand's e-commerce market scale is far ahead in Southeast Asia. According to the Thai E-Commerce Association Committee, "The growth rate of e-commerce in Thailand from 2017 to 2018 is about 17-18\%. Thailand's turnover in Southeast Asia is \$24.70 and \$100 million. In 2018, Thailand's overall e-commerce transaction scale was approximately 3.2 trillion yuan, a year-on-year increase of $14.04 \%$. Thailand's e-commerce market is expected to grow by $22 \%$ in 2022 , and it is estimated that it will achieve annual growth this year. With the support of the Thai government, the "Digital Thailand" plan [2] started in 2016 has brought companies a comprehensive digitalization of business and services. By 2020, B2C e-commerce is estimated to grow to US $\$ 1$ trillion [3]. Although there are a large number of Thais using e-commerce platforms, the Thai market is still immature, and there are still problems in development. The development of China's e-commerce market has entered a mature period. This article chooses to study Chinese and Thai consumers, compares and analyzes consumers' objects, environment, cultural differences, and the performance of consumers' online shopping behaviors, to obtain relevant and useful research conclusions.

Due to the existence of many differences in culture, history, region, etc. between Thailand and China, there are certain differences in the participation of their consumers in the field of ecommerce, such as differences in consumption habits and preferences of shopping platforms, which are worthy of study. Therefore, this article will use this article to first compare and analyze the consumer habits of the two countries, the differences in online shopping behaviors and the differences in online shopping culture behind them, and on this basis, make an in-depth comparative analysis of the current development of e-commerce in China and Thailand. the study. Based on the results of the analysis and research, this article will also put forward targeted and practical policy recommendations to provide more opportunities for discovery and strategic guidance for the development of e-commerce in Thailand and promote further development and progress of e-commerce in Thailand.

\section{Overview of the development of e-commerce}

\subsection{The status quo of e-commerce development in Thailand}

The Internet first entered Thailand in 1987 and was founded by the National Electronics and Computer Technology Center (NECTEC) of Thailand. By 1997, Thais slowly began to recognize e-commerce, but it was not very popular yet [4]. In the beginning, most people used it for developers, schools, governments, etc. during this period. Later, after a while, the Thai Ministry of Commerce promoted the commercial use of e-commerce because e-commerce has many benefits. According to statistics from the Ministry of Commerce in 1998, Thailand's ecommerce transaction volume reached 580 million U.S. dollars (approximately 22 billion baht) [5]. In the past ten years since then, in 2007, according to the National Bureau of Statistics of Thailand, $73.6 \%$ of e-commerce businesses are small businesses (businesses with no more than 5 people), and $85.5 \%$ of the B2C model. In 2006, Thailand's total sales through e-commerce were about 30,515.9 billion baht, most of which were government procurement e-Auction 
methods at 17,66683 billion baht, of which $57.9 \%$ was the B2B model, and 7972.6 billion baht was $26.1 \%$ was the B2C model [6]. According to the survey data of the National Electronics and Computer Technology Center (NECTEC) of Thailand, in 2010, the people who bought ecommerce accounted for about $57.2 \%$, an increase of $9.4 \%$ from the previous year [7]. The number of online shopping users in Thailand increased from 9.3 million in 2008 to 45 million in 2018. According to the statistics of the Thai Electronic Transaction Development Agency since 2014, the annual growth rate of Thailand's e-commerce value is about $8 \%-10 \%$ [8]. The scale of the e-commerce market continues to expand, and the number of online shopping platforms continues to increase. The mainstream online shopping platforms include Lazada and Shopee. Secondly, the scale of transactions continues to expand. The growth rate of the Thai ecommerce market ranks first in Southeast Asia. The prospect of e-commerce is huge [9].

In recent years, Thailand's total e-commerce transactions have made significant progress. According to the data released by the Thai Electronic Transaction Development Agency, the transaction volume of the Thai e-commerce market was 2,033,349.35 billion baht in 2014. By 2018, it had soared to $315,023.296$ billion baht, a growth rate of 54.9\% [10]. According to the prediction of relevant experts, by 2023, the transaction volume of Thailand's electronic market will exceed 6 trillion baht, which is expected to rank first in Southeast Asia. This shows that the added value of the e-commerce industry will increase every day. This growth rate is due to entrepreneurs' active participation in the e-commerce market and attempts to change and add new industrial model structures. Through the gradual establishment of the online transaction system, sales in Thailand and abroad will be increased. Use the advantages of the Internet to meet the diverse needs of consumers and increase more trade opportunities.

There is currently no e-commerce platform with domestic capital in Thailand, and all of them are foreign e-commerce companies. Priceza.com released the mainstream trading platform for Thai consumers to directly communicate with entrepreneurs through social commerce, such as Facebook and Instagram for more than $40 \%$ of purchases, and 35\% through Lazada, Shopee, etc. Secondly, there are many cross-border e-commerce platforms, such as Alibaba, Amazon, e Bay, etc., 25\% of which are online platforms of entrepreneurs. Experts predict that with the development of the times, Thailand's local e-commerce platform will appear in Thailand shortly. This is also the result that the Thai people and the government hope.

As shown in [Figure 1], in 2018, clothing was still the main product purchased by consumers, accounting for $44 \%$, which was the second-highest year-on-year increase of $33.7 \%$. IT equipment is also often purchased by Thai consumers through electronic platforms because many sellers are competing, so there are many discounts.

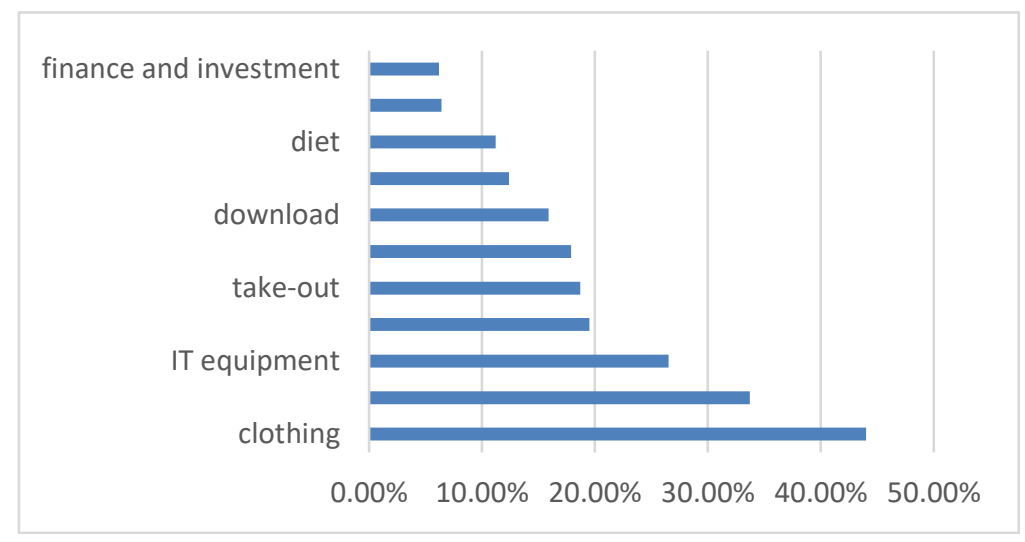

Figure 1. Main goods purchased in Thailand 
As shown in [Figure 2], the use of credit cards is the main payment method for e-commerce, followed by the use of mobile banking, which benefits from the popularization of mobile phones and the development and use of apps. ATM transfers account for the third most. Other payment methods tend to be traditional and are not compatible with the development characteristics of e-commerce, which is also one of the reasons for the slow development trend of e-commerce. In the future, if Thailand can have a transaction platform and payment parties such as "Alibaba" and "Alipay", it will make Thailand's e-commerce development more mature and complete. At present, Alibaba has also begun a strategic layout in Thailand, providing technical support. In the future, Thai e-commerce will be more popular among consumers.

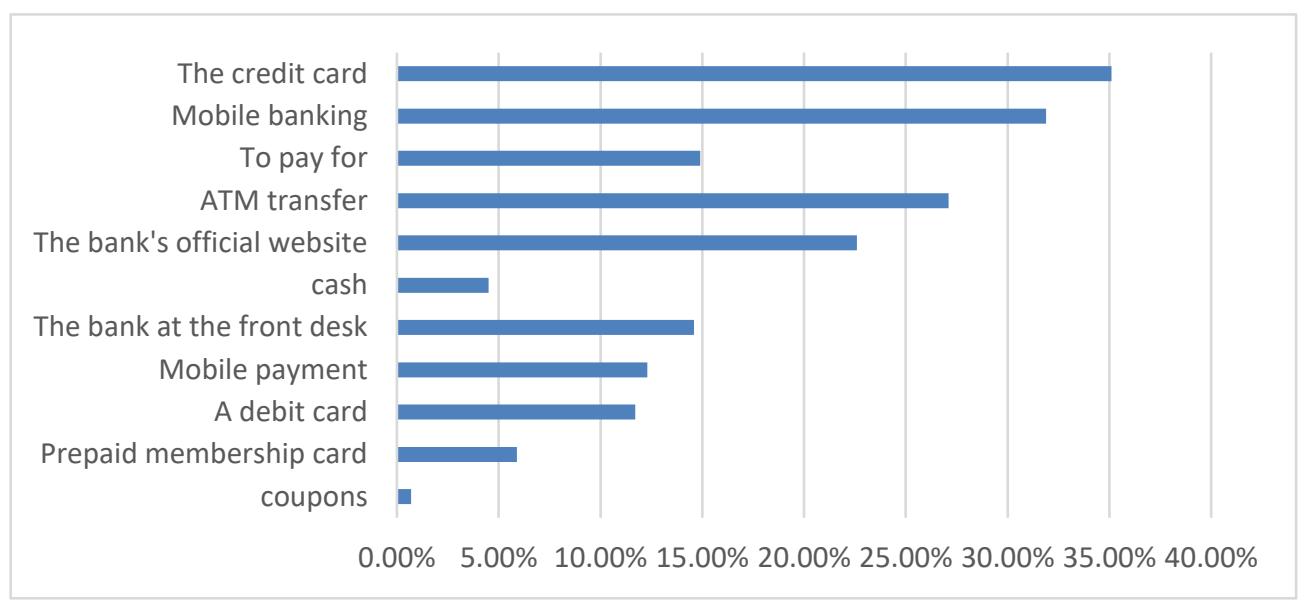

Figure 2. The main payment method for Thai consumers

The logistics system in Thailand was relatively backward in the past, but in recent years, the logistics system in Thailand has developed rapidly. Although the current logistics system is not yet sound and perfect, the government and private companies have seen the trend of ecommerce, so the two parties are slowly cooperating to develop logistics distribution. The system, such as SCG Express, Flash Express, Kerry Express, ship pop, sokochan, etc. Thailand's logistics can be divided into many sources, whether large national enterprises or small and medium-sized enterprises have different logistics methods, as shown in Figures 3 and 4 below:

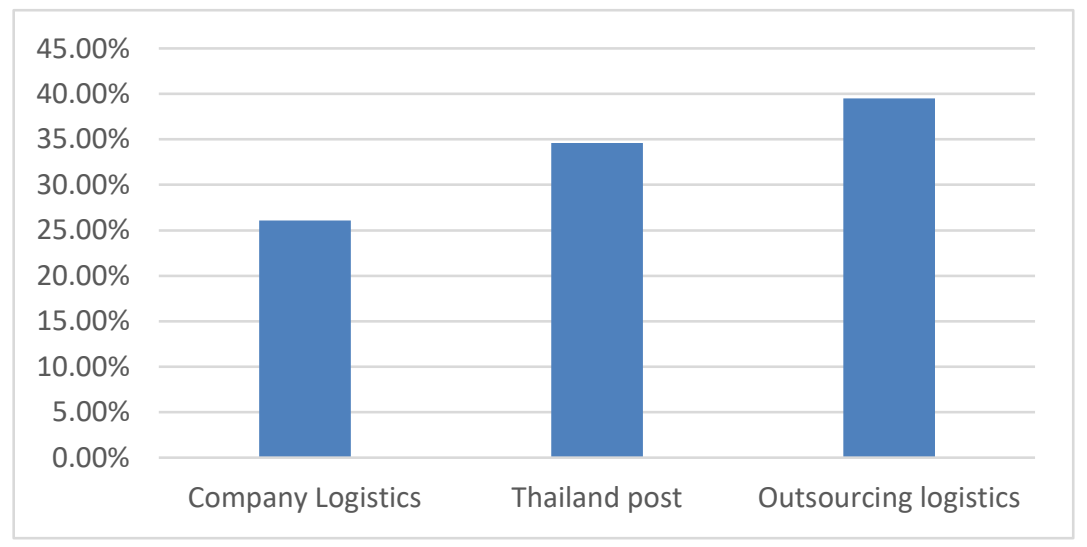

Figure 3. Logistics method used by big Thai companies 


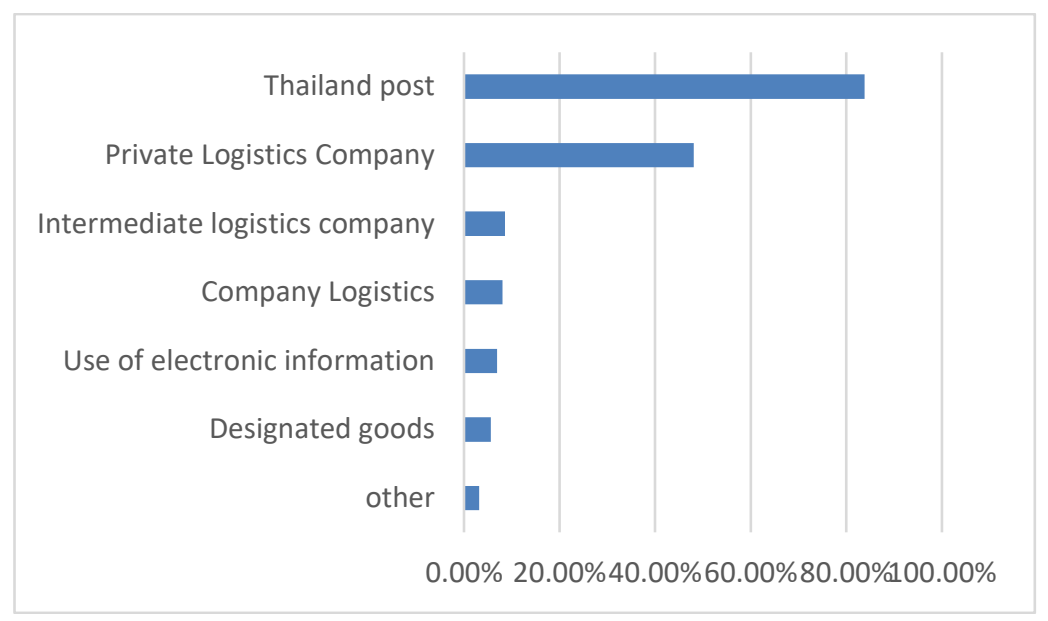

Figure 4. Logistics methods used by small and medium enterprises in Thailand

\subsection{Comparison of the development status of Thailand and China}

Compared with the development of e-commerce in Thailand, China's e-commerce is extremely mature and ranks among the best in the world's e-commerce field [11]. First of all, China's e-commerce development market is much larger than Thailand's, so the scale of transactions far exceeds Thailand. In 2018, there were 600 million online shopping users in China, and Thailand's total population was only 69 million. Secondly, China's e-commerce platforms with domestic capital, Thailand are all foreign e-commerce platforms [12]. Furthermore, China's e-commerce supporting facilities such as logistics systems, payment systems, etc. are already very mature, while Thailand's logistics system is rather chaotic, with high costs and low transportation efficiency; China's mobile payment is ahead of the world, and Thailand still adopts There are more ways of cash on delivery for savings cards and credit cards. Finally, China's e-commerce platform has an extremely complete variety of products. Almost all livelihood products can be purchased online, and there is a wide range of options. Thailand's e-commerce platform has relatively few types of products. On the whole, China's e-commerce development far exceeds that of Thailand [13].

\section{Investigation and analysis of online shopping behavior of Thai and Chinese consumers}

\subsection{Questionnaire design}

This questionnaire survey is to complete the questionnaire in Thailand during the summer vacation and conduct a questionnaire survey on the current situation of China-Thailand ecommerce application with local people in Thailand and Chinese. Understand Thai and Chinese participation in online shopping, understand Thai and Chinese online shopping behaviors, find out the advantages and disadvantages of Sino-Thai e-commerce development, and lay a foundation for studying Sino-Thai e-commerce online shopping behavior and research on Chinese products entering the Thai market basis.

The scope of this survey is Chinese and Thai people who use e-commerce to buy products. Young people are 18-50 years old, and each party has 200 people. The subject of this survey is to investigate the online shopping behavior, online shopping culture of Sino-Thai e-commerce, 
cultural differences between countries, and the development of e-commerce in the two countries through the form of questionnaires.

The survey time of this questionnaire is from July 20, 2019, to October 8, 2019. This questionnaire took about two months from designing a Chinese version for Chinese and a Thai version for Thais to translating it into Chinese.

The questionnaire is in Chinese and Thai, with a total of 29 questions and a total of 200 questionnaires. The main targets are the e-commerce sales status of the two countries, the shopping environment, shopping behaviors and shopping risks of the two countries, and the development of the e-commerce situation. It is hoped that through the above three aspects, a total of 29 indicators can accurately and objectively reflect the online shopping behaviors of Chinese and Thai consumers and the current personal basic situation of e-commerce shopping, to summarize the problems faced by Chinese and Thai consumers, and propose both parties Development opportunities and suggestions.

This survey method uses electronic questionnaire software, such as questionnaire star and Google to fill in. It consists of three parts: basic personal information, basic online shopping behavior, and online shopping determinants (including product factors, price factors, sales channel factors, promotion factors, and motivating factors).

\subsection{Statistical analysis of survey data}

The Chinese side issued a total of 200 points for this questionnaire, 198 valid questionnaires, and 2 invalid questionnaires, while the Thai side sent a total of 200 questionnaires, 191 valid questionnaires, and 9 invalid questionnaires.

Based on the research content, this article counts the gender, age, degree, occupation, and per capita monthly income of Chinese and Thai consumers. The proportion of girls of both consumers is higher than that of boys who love online shopping. Chinese girls account for 67.50\%, Thai girls account for 69.20\%; Chinese boys account for $32.50 \%$, and Thai boys account for $30.80 \%$. Both consumers are girls who prefer to shop. The 200 Thai female consumers in the survey accounted for a higher proportion of Thai female consumers than Chinese consumers.

The age of online shopping for both parties is mainly 21-29 years old. Chinese consumers account for $73.5 \%$ and Thai consumers account for $47.70 \%$. Except for consumers aged 21-29 and over 50, Thai consumers prefer online shopping to Chinese consumers. It can also be seen from the figure below that fewer consumer over 40 years old are shopping online. The survey shows that Thailand and China have the highest proportions in the 21-29 age group, mainly because this group of people is relatively young and does not have too much pressure. In addition, I am more willing to accept new things, such as online shopping. For this reason, most of these people are busy with work, and relatively little time can be spent shopping in physical stores. Therefore, users in the 21-29 age group account for the highest proportion.

The consumption degrees of both parties are mainly undergraduates and masters. Chinese consumers with a bachelor's degree accounted for $26.5 \%$, and Thai consumers accounted for 65.8\%; Chinese consumers with a master's degree accounted for $61 \%$, and Thai consumers accounted for $19.1 \%$.

The most obvious online shopping consumer group in China is $55.5 \%$ of students, while $31.4 \%$ of Thai consumers are civil servants. This is related to the social environment because most of China goes to graduate school after graduation, but many universities in Thailand work first after graduation and continue to graduate after working for one or two years. 
The per capita income of Chinese consumers is mostly 53\% below 3,000 yuan, because the occupations of the above consumers are mainly students, while the top two per capita incomes of Thai consumers are almost below 3,000 yuan, which is $25.6 \%$. The $22.1 \%$ at $3,001-4,000$ yuan is because the highest occupation in Thailand is civil servants and students.

Consumers on both sides have shopped online, $99 \%$ of Chinese consumers and $96 \%$ of Thai consumers. Thai consumers have never used online shopping a little bit more than in China, because Thailand's e-commerce development is slower than in China, so some people will not be used to online shopping.

Consumers on both sides use mobile phones to make more purchases than all online channels, with $93 \%$ of Chinese consumers and $94 \%$ of Thai consumers. Chinese consumers use notebook computers at $5.5 \%$, and Thai consumers use tablet computers at $2.5 \%$.

The reason why consumers on both sides did not shop online was that they were worried about receiving fake or defective or poor-quality products. Chinese consumers accounted for $67.5 \%$, and Thai consumers accounted for $61.3 \%$. Secondly, $64.0 \%$ of Chinese consumers are worried about receiving products that are different from those described on the Internet, and $62.3 \%$ of Thai consumers. In addition to other reasons, there are not many product varieties on the online shopping platform. The inability to meet their own needs is the reason that affects consumers on both sides not to shop online. Chinese consumers are $9 \%$ and Thai consumers are $12.3 \%$.

The reason why consumers from both sides shop online is the most convenient and fast and can save time. Chinese consumers are $80.5 \%$ and Thai consumers are $71.8 \%$. Second, the reason why the price is cheaper than in physical stores is $64.0 \%$ of Chinese consumers, and $62.3 \%$ of Thai consumers think that they can buy it anytime, anywhere. This is also the second most important reason for Chinese and Thai consumers. Among other reasons, 19\% of consumers in China and Thailand felt that they could check the quality of their products from product reviews first, and $32.3 \%$ of them did not have any products they needed nearby, which was the least reason for Thai consumers to choose to shop online.

[Figures 5] and [Figure 6] show that the top three most popular platforms for online shopping by Thai consumers are Lazada, Shopee, and Facebook with 70.4\%, 68.4\%, and 65.3\%. These three e-commerce platforms are not established domestic e-commerce platforms.

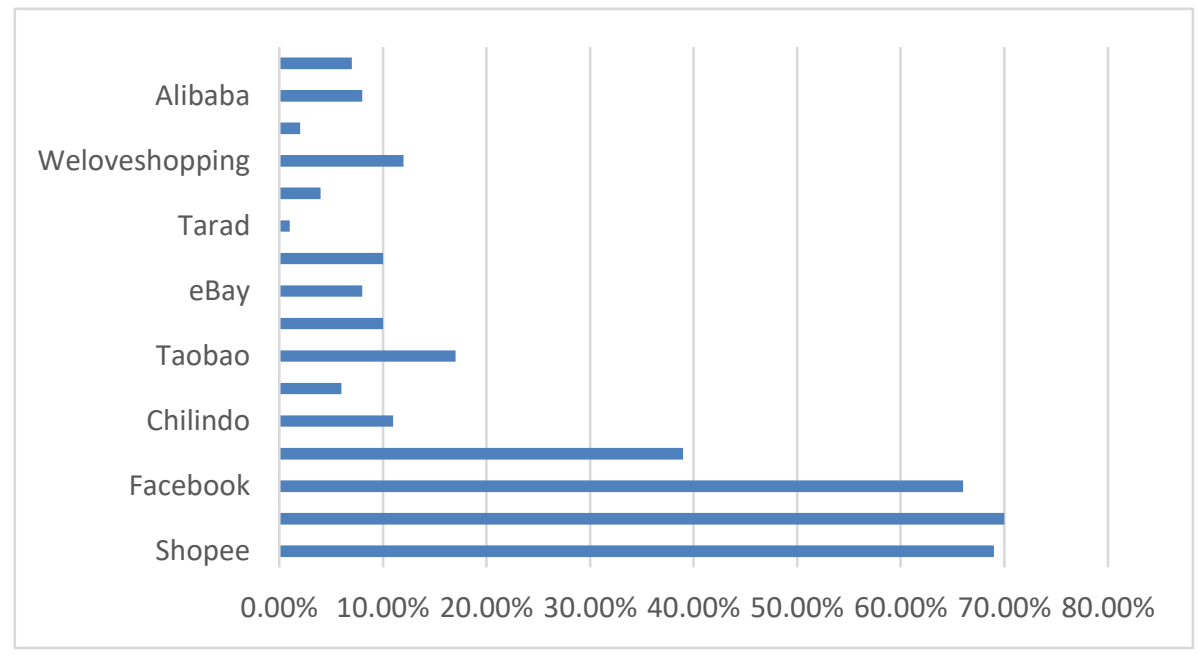

Figure 5. Thailand's leading online shopping platform 


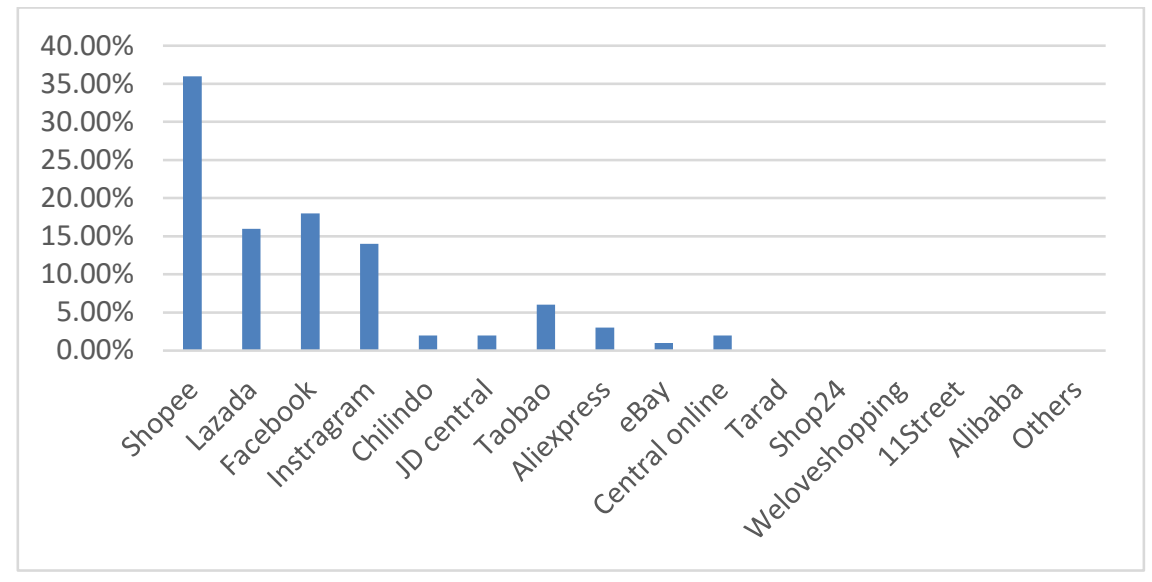

Figure 6. Thai consumers use the most platforms

[Figures 7] show that Chinese and Thai consumers buy clothing products online, $87 \%$ of Chinese consumers and $73.1 \%$ of Thai consumers. The next Chinese consumers most often buy shoes and cosmetics at $82 \%$ and $63 \%$, but Thai consumers most often buy bags and shoes at $45.6 \%$ and $41.5 \%$. In Figure 6, consumers on both sides are most obviously buying goods online, with the most being clothing, with $60.5 \%$ of Chinese consumers and $46.9 \%$ of Thai consumers.

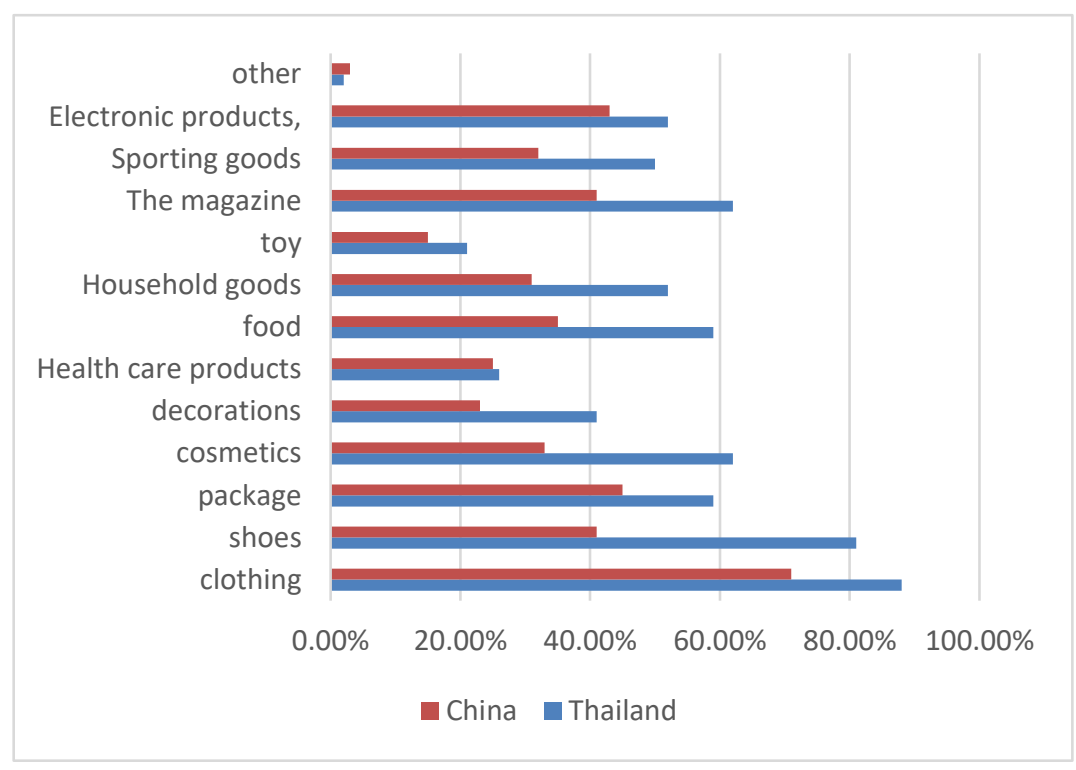

Figure 7. China and Thailand consumers to purchase goods at most

Consumers from both sides buy goods online on average 2-4 times a month, with more than half of Chinese consumers being 53\% and Thai consumers being $46.7 \%$. It can be seen from the figure below that there are 5-7 online purchases and more than 7 times a month. Chinese consumers are $12.5 \%$ and $17.5 \%$, because of the development of China's e-commerce and the social environment, such as payment methods, e-commerce platform systems, and other related provisions Consumers bring great convenience and confidence. 
Chinese consumers generally use Alipay to pay up to 78\%, because Alipay is currently the most convenient and most complete payment method in China [16]. Alipay has payment cooperation with many other platforms, so this reason makes many consumers choose to use Alipay the most. Thai consumers use mobile payments, including mobile banking, the most, at $39.3 \%$. Credit/debit cards and cash on delivery are also popular choices among Thai consumers, at $27.6 \%$ and $20.9 \%$. At present, most people have credit cards, and consumers can get discounts from banks. Some points can be exchanged for various things, and cash on delivery allows consumers to buy with confidence. Receiving, inspecting, and paying later, if you are not satisfied or you can refuse to accept the goods, is also very convenient for consumers.

More than half of Thai consumers often compare the price and quality of products at $58.4 \%$, while half of the Chinese consumers occasionally compare the price and quality of products at $50.5 \%$. However, Thai consumers occasionally compare the price and quality of products at 35 . $\%$. If the result of comparing the price and quality of the product is not available, $16.5 \%$ of Chinese consumers do not compare, but only $6.6 \%$ of Thai consumers do not compare the price and quality of products.

The main factor that most influences consumers on both sides to make online purchases is that the store is very popular, has a good evaluation, and is trustworthy, with $43.5 \%$ of Chinese consumers and $45.1 \%$ of Thai consumers. High store reviews and product reviews also have many factors that promote purchases for consumers on both sides, $32.5 \%$ of Chinese consumers and $29.2 \%$ of Thai consumers. In addition, the factors of inquiring and feedback from customers who have bought are the least for Chinese consumers.

\subsection{Comparison of differences in online shopping behavior between China and Thailand}

Based on the above research, although there are some problems in China's e-commerce industry, it is undeniable that its development and maturity are very mature, and Chinese people have become part of the daily life of online shopping. Chinese netizens not only buy products such as small home appliances and daily necessities but now even cars and real estate can be purchased online [18][19]. Now in China, no matter what you need, you will first check it on the e-commerce platform. Secondly, China's online shopping group and consumption power are very strong. Because Chinese consumers are relatively young, they are familiar with network technology and online shopping systems and are more willing to learn and accept new things. Just look at the transaction volume of online shopping festivals such as "Double 11" and "JD 618" each year to understand the degree of craziness [20]. In contrast, in Thailand, although Lazada, Shopee, and other e-commerce companies are becoming more and more accepted by everyone, they are still immature. At the beginning of this century, when eBay, Amazon, Taobao, JD.com, and others seized the market, Thailand had Lazada and Shopee online shopping. There are also e-commerce platforms such as Facebook, Instagram, Chilindo, JD Central, Welove shopping and Fangguo, Panhai, Zhibi, etc., but they are not as big as Lazada and Shopee in scale, and the products sold are not as complete. The security of buying goods on Facebook and Instagram is relatively low. Secondly, because some consumers have limited Internet access, they cannot make online shopping [21][22][23]. Research shows that the proportion of Thai people over 50 who purchase online is less than that of Chinese consumers, but the proportion of Thai consumers aged 30-39 who buy products online is higher than that of Chinese consumers. Most of these people are office workers and have online purchasing power. The purchase amount ratio is higher than that of the Chinese. Thailand's e-commerce is still in its infancy, so the proportion of online shopping in Thailand is lower than that in China. Secondly, Thailand's e-commerce platform has fewer types of goods than China, and the quality 
of goods is even more uneven, so there is still a large number of people who do not fully accept online shopping. Therefore, this is also the reason why Thai Facebook and Instagram shopping are still widely accepted. Although the security of Facebook purchases is low, Facebook has a high market share in Thailand and consumers are more familiar with the operating procedures. In addition, there are no complicated steps to purchase on Facebook and Instagram. You only need to select the purchased product, send a text message directly to the seller to complete the payment, and finally wait for the product [24]. Shopee and Lazada's purchase steps are relatively cumbersome. Facebook and Instagram shopping is similar to micro-businesses in China. There are a large number of groups in Thailand, mainly selling small items such as clothes, and the sales circle is very small. But it is precise because the circle is small, so the quality will be relatively guaranteed. Generally speaking, China's e-commerce is much more mature than Thailand's, and its national recognition is also much stronger. However, the market in Thailand and even Southeast Asia still has huge potential.

\section{Thai and Chinese e-commerce faces problems and opportunities}

\subsection{Facing problems}

Although the Thai e-commerce market has been well improved, there are still major problems in Thai e-commerce. The main problems of e-commerce in Thailand are payment methods, logistics and transportation systems, and lack of talent. In terms of payment methods, there is no unified payment system in Thailand. Therefore, payment methods for online shopping in Thailand are diverse and confusing. In addition, the security of Thailand's payment system is also low [25]. In terms of logistics and transportation, there are many private logistics companies in Thailand, but the costs are relatively high, the product delivery cycle is long, and they are easily damaged during transportation. In addition, Thailand's largest national post office must also be adjusted in time to prepare to support e-commerce, and find ways to improve transportation and the state of products after delivery at the lowest cost. In terms of talent management, Thailand still lacks talents who can truly lead the development of e-commerce. Secondly, the training of e-commerce talents in Thailand is also relatively backward. Among the e-commerce platforms, the Thai e-commerce platform has poor system stability, the Internet servers are not advanced enough, and the e-commerce customer service is poor. In terms of product types, Thailand's online shopping platform has a limited variety of products and relatively high prices. The introduction and details of the products on the Thai e-commerce platform are not prominent enough, and the information is not comprehensive. It is difficult for consumers to fully understand all the information about the purchased products.

China has the most developed e-commerce system in the world, not only in terms of products but also in online shopping platforms. At present, China's online shopping culture has penetrated all aspects of consumers. The infrastructure of e-commerce has also matured, such as payment, logistics, after-sales, and so on. However, according to the results of the questionnaire survey, China's e-commerce malls still have problems that need to be resolved. The biggest problem is the quality of the product. Take Taobao as an example. For example, you need to buy a pair of Nike sneakers. There are hundreds of shops with the same style, and the price and quality are even more uneven. Therefore, when many consumers buy branded products on Taobao, they are most worried about buying fake and parallel imports. Therefore, in the future, China's e-commerce market must pay attention to issues such as market regulation, strict control of product quality, and product authorization. 
Based on the questionnaire regression, this article found that the most prominent problem for Chinese and Thai consumers in the online shopping process is the lack of integrity of the merchants. Consumers worry about getting fake products, defective products, or product quality deviations that are different from online descriptions. Some unscrupulous merchants used inconsistent exaggerated photos, false information, illegal publicity, vicious price wars, and other methods to mislead consumers when they promoted their products to mislead consumers to choose to buy, and put some defective products, fakes, and poor-quality products. The goods are distributed to consumers. However, customers lack judgment and can only choose products based on their feelings and advertising, and they can buy products with poor quality and inconsistent advertising. Quality issues are the primary issue that consumers of both sides consider being the most important issue in online shopping.

With the development of network technology, there are still insecurity problems in online shopping, especially in terms of payment. China's online payment system has a more mature and realistic foundation, but there will inevitably be security risks in the process of using thirdparty payments. At present, the most popular payment methods used by Chinese consumers for online shopping are Alipay, WeChat, and credit cards. However, there is inevitably a problem that a user can register six numbers. For example, the former owner used this number and did not unbind the mobile phone number. New users can't use or can use but are not registered users. In Thailand, online shopping payment methods are generally through mobile payment, including online banking, with the use of credit cards as the second option. As Thailand's online payment technology still needs to be greatly improved, consumers have no corresponding accountability and insurance claims through third-party payment. The results of the questionnaire show that the security of China's third-party payment system is higher than that of Thailand's current payment system.

\subsection{Development opportunities of Sino-Thailand e-commerce}

Currently, we understand the online shopping behaviors of Chinese and Thai consumers. From the above survey results, it can be seen that Chinese consumption considers that good product quality and price are the first factor. Thai products are also very popular among Chinese consumers. Therefore, if they are sold in China, there is a high probability that Chinese consumers will be interested. Buy, but in terms of price, there are restrictions on shipping costs and delivery time, such as higher shipping costs and slow delivery time. Therefore, it is time to develop integrated warehousing and logistics in China, especially the cooperation between the national government and the Chinese government to support the establishment of warehouses. The advantage of this is that when the purchase order and transportation costs are reduced, the products can be immediately distributed in the country. According to Azoya's research on understanding Chinese customers, the average annual growth rate of Chinese online shopping behavior from 2014 to 2018 was 25\%. Most women and workers between the ages of 25-34 are consistent with the above research results. In addition, China's entry into the elderly society is the most serious in the world, which can be reflected in the number of Chinese over 65 years old. Arouse the demand for buying Thai health products, medicines, and cosmetics, and tend to buy more online. Therefore, this is a good opportunity for Thailand to penetrate the entire target population, including young people, women, and the elderly, and it will make the visit of Thai products easier without a long wait.

As the current Chinese consumers' decision to buy products is more about quality. Therefore, this is a good opportunity for Thai products with high-quality or niche markets, in line with China's cross-border e-commerce policy support. Hope to import high-quality products into the 
domestic market. In the electronic market of the trading platforms of major Chinese brands, such as Tmall and JD.com, it is an opportunity for Chinese consumers to easily identify Thai companies and products, thereby gaining opportunities to promote Thai products. According to data from AliResearch, the top 5 Thai products that are most popular among Chinese consumers are cosmetics, baby products, health food, clothing/shoes, and electronic products, which account for $60 \%$ of China's cross-border e-commerce. Therefore, this is a once-in-a-lifetime opportunity for Thai companies, whether it is for cosmetics manufacturers, skincare products, and processed fruits such as dried mangoes, crispy durians, and health foods.

\section{Conclusion}

This article takes China and Thailand as the research objects and uses literature review, survey, and comparative analysis to analyze the online shopping behaviors and characteristics of Chinese and Thai consumers, including basic consumer information, online shopping behaviors, and consumer decision-making factors. Summarize the differences in behavior between the two parties. Compared with China, Thailand's e-commerce still has a big development gap. For the development of e-commerce in Thailand, the contradiction of platform construction is more prominent to be resolved. At present, online shopping has become the most important part of consumers' daily life, and it is convenient for consumers to buy no matter where they are. In the future, consumers will use more and more online shopping. This article also proposes that for the development of e-commerce in Thailand, it is necessary to attach importance to college students, an important consumer group, and meet its multi-level and multi-faceted needs through higher-quality development. Thailand's current work should focus on the construction of electronic platforms and related supporting network environments.

\section{References}

[1] A. Wasinon, "E-commerce strategy with Thai business development in the digital age," The Office of Industrial Economics in Thailand, pp.15, (2018)

[2] A. Watthanakul, "Factors relating to product buying of the consumer through popular e-commerce website in Thailand," Srinakharinwirot University, pp.35-42, (2012)

[3] W. Khan-am and S. Singrang., "Consumer behavior toward purchasing choices through electronic media," Rajamangala University of Technology Thanyaburi, (2012)

[4] K. Jitwat, "Online shopping factor and website quality affecting the decision to purchase products via Lazada of consumers in Bangkok," Bangkok University, pp.3-7, (2016)

[5] C. Comegys and M. L. Brennan, "Students' online shopping behavior: A dual-country perspective," Journal of Internet Commerce, vol.2, no.2, (2003)

[6] P. Loketkrawee and V. Bhatiasevi, "Elucidating the behavior of consumers toward online grocery shopping: The role of shopping orientation," Journal of Internet Commerce, vol.17, no.4, (2018)

[7] P. Chuatchunoo, "Factors affecting consumer buying decisions about goods on social media," Thammasat University, pp.2-3 and pp.8-12, (2016)

[8] F. Driediger and V. Bhatiasevi, "Online grocery shopping in Thailand: Consumer acceptance and usage behavior,” Journal of Retailing and Consumer Services, pp.48, (2019)

[9] J. Kiadrasamee, "Factor affecting the decision making on purchasing products from the online application in Bangkok," Metropolitan Region, Thammasat University, pp.28-35, (2015)

[10] K. Udomsab, "E-branding development for successful of e-commerce case study: E-commerce of Thailand," Thammasat University, pp.27-30, (2010)

[11] T. Shao, "On the development of China's foreign trade cross-border e-commerce," Journal of Hubei Open Vocational College, vol.32, no.12, pp.108-109, (2019) 
[12] H. Xu and M. Hui, “Analyze the characteristics and problems of college students' online consumption from online shopping behaviors - Taking a university as an example," Shanxi Normal University News (Social Science Edition), vol.40, no.2, pp.128-130, (2013)

[13] B. Ma and N. Yu, "Development status and trend analysis of Thailand's e-commerce industry," Shang, no.12, pp.121, (2015)

[14] F. Li and H. Yi, "Research on my country's cross-border e-commerce development status, problems and its export trade effect - taking my country's export trade to the EU as an example," Business Economics Research, no.17, pp.138-141, (2019)

[15] P. Zhang, "Research on the development and policy of cross-border e-commerce in Thailand," Guangxi University, (2015)

[16] J. Han, "Research on the internationalization development of cross-border e-commerce in my country," Capital University of Economics and Business, (2018)

[17] J. Yang, 'Analysis of the status quo of my country's cross-border e-commerce development and discussion of countermeasures,” China Business Forum, no.15, pp.25-26, (2019)

[18] J. Rilan, "The development direction and innovation path of cross-border e-commerce logistics model," Modern Business, no.31, pp.35-36, (2017)

[19] S. He and X. Li, "Research and exploration of my country's cross-border e-commerce development under the background of "One Belt One Road"," National Circulation Economy, no.23, pp.26-28, (2019)

[20] J. Lv, "Analysis on the development strategy of cross-border e-commerce and logistics integration," Chinese and Foreign Entrepreneurs, no.24, pp.48-49, (2019)

[21] Q. Ge, "Research of development Situation, existing problems, strategy, countermeasure and supporting policy for Ningbo cross-border electronic commerce," Wuhan Zhicheng Times Cultural Development Co. Proceedings of the International Conference on Mechatronics Engineering and Information Technology (ICMEIT 2016), pp.185-188, (2016)

[22] W. Surangkana, “E-commerce trend 2562,” Data Digital Intelligence, pp.4, (2019)

[23] J. Lv, "Analysis on the development strategy of cross-border e-commerce and logistics integration," Chinese and Foreign Entrepreneurs, no.24, pp.48-49, 2019, Watcharaporn Jhiengkhong, Factors Influencing the Decision in Purchasing Online: Focusing on Channel Pick-up Store," Burapha University, pp.24, (2016)

[24] J. Lv, "Analysis on the development strategy of cross-border e-commerce and logistics integration," Chinese and Foreign Entrepreneurs, no.24, pp.48-49, Weeruthai Kittipiphatphuti, "E-commerce: New Opportunities for Thai Businesses" https://www.bot.or.th/Thai/ResearchAndPublications/DocLib_/Article18_05_58_.pdf

[25] J. Lv, "Analysis on the development strategy of cross-border e-commerce and logistics integration," Chinese and Foreign Entrepreneurs, no.24, pp.48-49, Wenjuan He, Yuming Xu. "Cross-Border Electronic Commerce Development Present Situation and the Innovation Research in China, (2019) 
This page is empty by intention. 